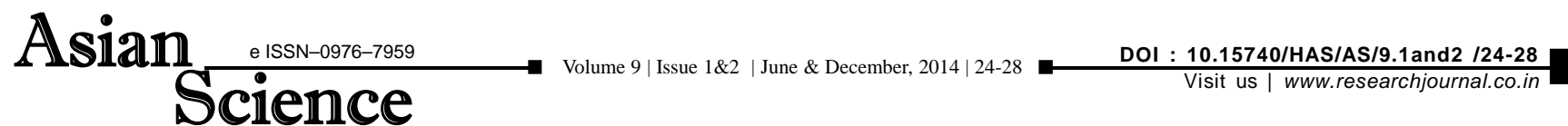

RESEARCH PAPER

\section{Temperature measurement for hydrogen gas in turbulent jet diffusion flame with swirler of angle $45^{\circ}$}

\author{
AMIT KUMAR GUPTA \\ Department of Chemical Engineering, Babu Banarsi Das Institute of Technology, LUCKNOW (U.P.) INDIA \\ (Email: amitguptahbti@rediffmail.com)
}

\begin{abstract}
Temperature measurement of $\mathrm{H}_{2}$ gas was investigated experimentally in turbulent diffusion flame with co-flowing air stream with swirler. The air velocity changes from slow to high flow rate. Reynolds number is varying throughout the process from laminar to turbulent region. Results showed that the temperature decreases with increase the air flow rate and also temperature decreases as decrease in M.F.R. and equivalence ratio. Flame stability increases with increasing the hydrogen content in the hybrid fuel mixture.
\end{abstract}

Key Words : Hydrogen gas, Temperature, Flame

View point paper : Gupta, Amit Kumar (2014). Temperature measurement for hydrogen gas in turbulent jet diffusion flame with swirler of angle $45^{\circ}$. Asian Sci., 9 (1\&2): 24-28. 